\title{
Characterisation and Analysis of Alternate Hybrid Material for two Wheeler Mud Guard
}

\author{
J. Parivendhan Inbakumar ${ }^{1}$ and S. Ramesh ${ }^{2}$ \\ ${ }^{1}$ Department of Mechanical Engineering, Sathyabama Institute of Science and Tech., Chennai, India \\ ${ }^{2}$ Department of Mechanical Engineering, Presidency University,Bengaluru, India
}

\section{ABSTRACT}

The purpose of a mud-guard in a vehicle is to keep the tyres of the vehicle away from stones, mud and debris that causes small damages to the vehicle. If the design of the mud-guard is weak, splashing of mud and erosion of material coating of the mud-guard takes place while driving the vehicle. Therefore, it is necessary to design a robust mud-guard with desirable mechanical properties to overcome the above disadvantages. In this work, mud-guard of a motorcycle is manufactured by using a composite material made by combining fibres (hybrid) such as hemp fibres and palm fibres. The above mentioned fibres are reinforced as composite materials using epoxy as the matrix material. Initially, the composite material is fabricated and tested for its mechanical properties as per the standards. Optimum tensile strength value was observed for HP50 to be $113 \mathrm{Mpa}$. The material with optimum volume percentage was selected for the modelling of the mud-guard. The modelling was done and analysed for its mechanical properties such as stress, strain and deformation with appropriate material properties using ANSYS software. From the analysis, the maximum equivalent stress, equivalent elastic strain and the total deformation are found to be 9.417 × $106 \mathrm{~Pa}, 5.9772 \times 10-6$ and $6.493 \times 10-7 \mathrm{~m}$ respectively and they are found to be better when compared with the properties of the existing mud-guard. Moreover, the composite material used is eco-friendly and inexpensive which is an advantage for commercial usage of the mud-guard.

KEY WORDS: ECO-FRIENDLY, EPOXY RESIN, HEMP FIBER, PALM FIBER, AND ROBUST MUD-GUARD.

\section{INTRODUCTION}

Focus on natural fiber composites has drawn the attention of many researchers (i.e., bio composite), basically they are composed of natural resins or synthetic resins reinforcement of natural fibers. (Ayyappa et al., 2020) has selected two sets of natural fiber reinforcements like banana/ pineapple and hemp/ flax. Samples were fabricated by hand layup method and tested. Using Universal Testing Machine (UTM) the flexural properties

\section{ARTICLE INFORMATION}

${ }^{*}$ Corresponding author email: la

Received 10th Oct 2020 Accepted after revision 27th Dec 2020 Print ISSN: 0974-6455 Online ISSN: 2321-4007 CODEN: BBRCBA

Thomson Reuters ISI Web of Science Clarivate Analytics USA and Crossref Indexed Journal

\section{Clarivate
Analytics}

NAAS Journal Score 2020 (4.31)

A Society of Science and Nature Publication,

Bhopal India 2020. All rights reserved.

Online Contents Available at: http//www.bbrc.in/

Doi: http://dx.doi.org/10.21786/bbrc/13.15/48 were tested, the interlaminar shear strength and moisture absortion test of the fabricated composites were also tested. The combination of fibers, its effect on the flexural and the displacement on loading were analyzed from the breakup vs weight fraction results obtained from testing.

The results showed the different combinations, hybrid fibers showed improved flexural strength and flexural modulus. Pure fiber reinforcement showed lesser value. Generally, the hybridization of composites improves the mechanical properties. Usage of natural fibers has advantageous properties; they are a less dense material yielding relatively less weight composites with good specific properties. (Sathyanarayana et al., 1983) Natural fibers are economical and can be easily processed, being a good renewable resource, that has reduced the dependency on foreign and domestic petroleum oil. 
In this paper, importance of the natural fibers have attracted as a potential materials for structure. The attractive plus point of natural fibers terms of material usage has made its availability more demanding. (Padma Priya et al., 2005) has developed Waste silk fabricreinforced epoxy laminates by varying content of silk fabric. The mechanical properties like tensile strength and flexural strength of the composites were determined. These properties were found to increase, with increase in silk fabric content. These composites also showed good chemical resistance to some acids, alkalies, and solvents. The interfacial bonding between the reinforcement and the matrix was examined using SEM technique. (Murali Mohan Rao et al., 2007) studied the tensile, flexural and dielectric properties of composites made by reinforcing vakka, date and bamboo as a new natural fiber into a

Table 1. Labelling of composite materials

\begin{tabular}{|l|l|l|l|}
\hline S.No & Label & $\begin{array}{c}\text { Composite } \\
\text { Details }\end{array}$ & $\begin{array}{c}\text { Fiber } \\
\text { Vol(\%) }\end{array}$ \\
\hline 1. & NE & Neat Epoxy & 0 \\
\hline 2. & HP20 & Hemp + Palm fiber & 20 \\
\hline 3. & HP30 & Hemp + Palm fiber & 30 \\
\hline 4. & HP40 & Hemp + Palm fiber & 40 \\
\hline 5. & HP50 & Hemp + Palm fiber & 50 \\
\hline
\end{tabular}

polyester resin matrix. The fibers extracted by manual processes have been used to fabricate the composites.

These composites are tested for tensile, flexural and dielectric properties and compared with those of other composites fabricated from sisal, bamboo and banana made under same conditions. Epoxy-based composite exhibit lower wear loss than polyester-based composite. From the literature review, it is found that hybrid composite prepared using natural fibres are found to be a possible source of replacement for synthetic reinforcement polymer composite. Since, they can be utilised for the various application. Hence in this work, hybrid composite of hemp and kenaf fibers were fabricated. Based on the optimum values of the mechanical properties obtained, the modelling and analysis of the mud gaurd was done. The composite are tested for the equilateral stress, equilateral strain and total deformation behaviour by providing the load and speed parameters.

Fabrication of Composite Materials: After the selection of materials, fabrication of material was done. Two categories of specimen were fabricated, untreated fibers reinforced specimen and treated fiber rienforced specimen. The treatment of fibers were done so that the surface modification is possible for the fibers that may help in improvement of adhesion properties in the fabrication. Alkali treatment was done with $4 \%$ sodium hydroxide. After the treatment the fibers are sundried 48 hours to remove the moisture in the material.

Table 2. Mechanical properties of Hybrid composite

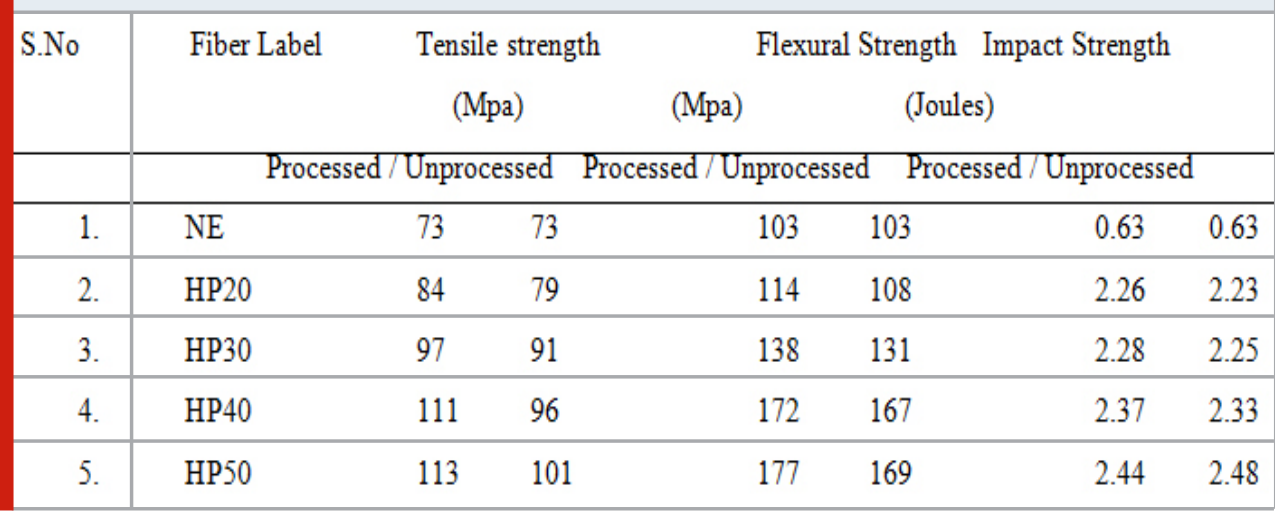

Figure 1: Morphology of the Experimental work

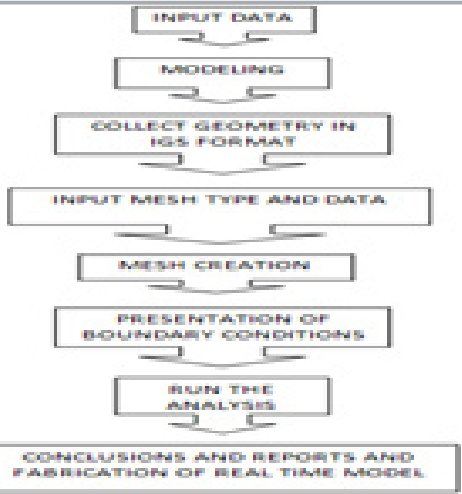

Figure 2: Modeling of Part

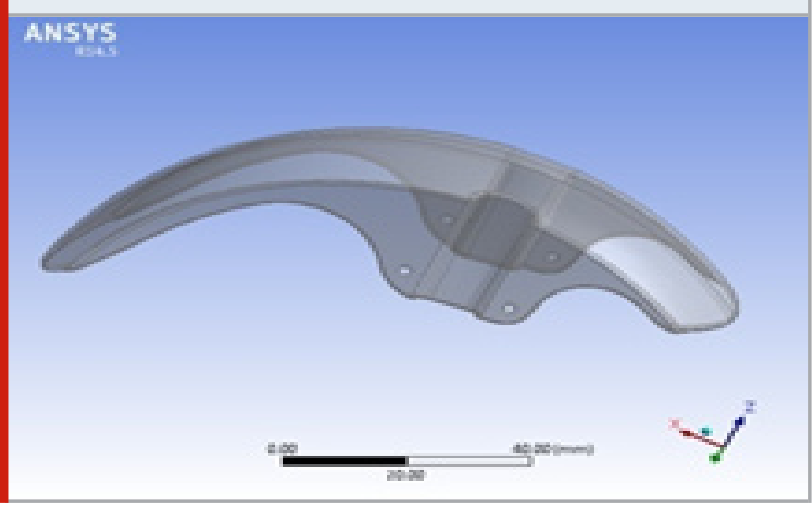


Figure 3: Mesh Generation of part

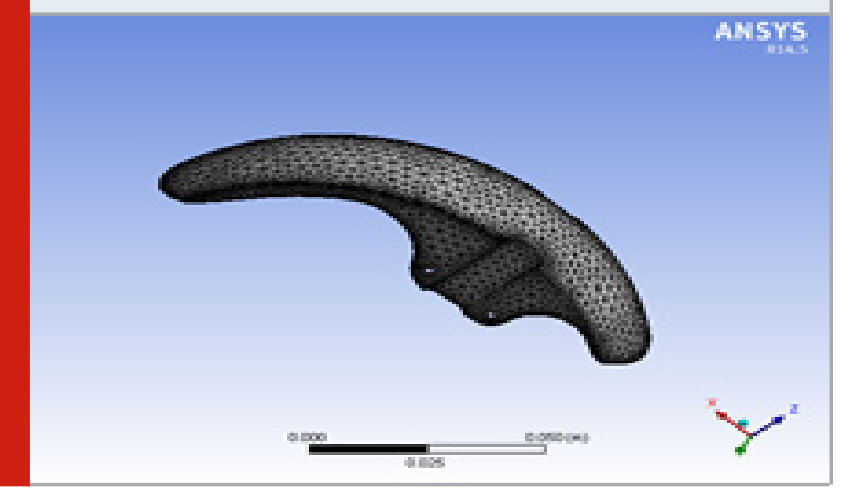

At various fiber loading conditions the fibers were fabricated. Different volume percentage like 20\%, 30\%, $40 \%$ and $50 \%$ of (Hemp + Palm) fiber fiber loading was done and samples were obtained for testing to know the influence of the fibers in the epoxy matrix material. Equal proportions of hemp and palm fiber where added to fabricate the hybrid composite laminate. After the resin and fiber laying was done and the material was left to cure for 24 hours. The samples obtained were tested for their tensile properties, flexural and impact properties. All the testing were carried according to the ASTM standards.

The procedure for the fabrication and preparation of the samples for the testing of the composite material are as follows.

- $\quad$ Surface modification of hemp and palm fiber

- Mould preparation

- Resin preparation for the composite material

- Fiber stacking in the mould

- Removal of air bubbles

- Curing the prepared material

- Specimen preparation for the testing of composite materials

Characterisation of Composite Materials: The following procedure were carried out for the preparation of the specimen to be tested under ASTM standard. The results were obtained and the observations were tabulated. From the observations it was found that the natural fibers processing have improved the mechanical properties of the material. The relation of the fiber loading as well as the treatment are clearly shown in the tabulations. The lower hemp/kenaf fiber loading showed lower values as the availability of the fibers are less hence load bearing capacity is lesser.

Morphology for Modeling of the Mud Gaurd: The selected materials was given as input data for the model of the mud guard. The properties were assigned for the materials. Mesh creation was performed for the analysis of the part. Additionally boundary conditions like supports and loads were provided for the analysis. The analysis was carried out for Two materials ABS and hybrid (hemp, glass and epoxy). The prototype was also fabricated on completion of the analysis.

\section{a. Steps Involved in the Analysis of Mudguard}

1. Create a model of mud guard using key points in ANSYS and provide suitable dimensions (thickness, area etc.)

2. Assign the properties of the material for the model created.

3. The model generated is meshed using trianglar coarse mesh.

4. Boundary conditions were set according to the application.

5. Suitable support and load conditions were applied.

6. Direction of the load was also assigned for the better solution.

7. The model was solved using ANSYS and the following results were obtained.

Figure 4: Equivalent stress, Equivalent strain and Total deformation of the Hybrid Composite Part

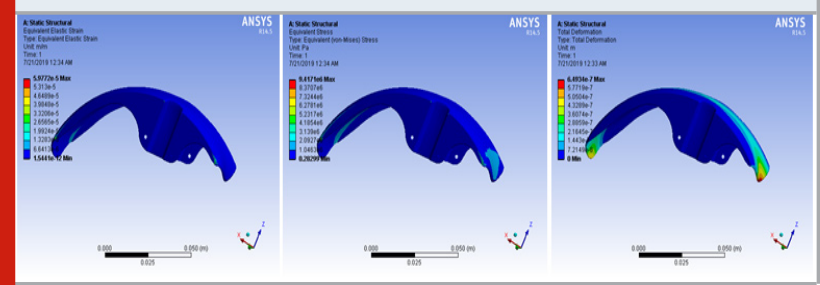

Figure 5: Protype fabrication

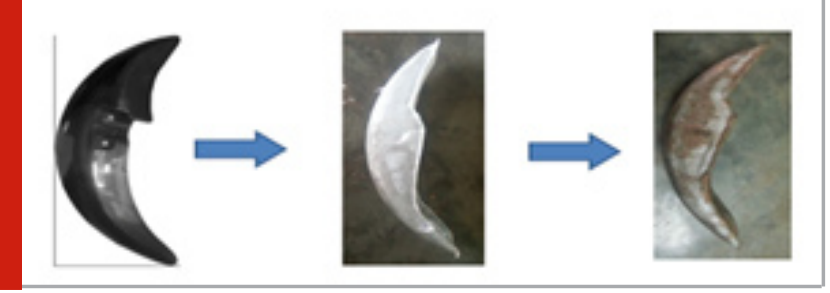

b. Prototype Preparation of the Mud Guard: The hybrid composite material was fabricated by hand layup method. The agent that is used the release the component from the mould is hard wax. It is equally spread over for better release of the component from the mould and it is left to dry for about 30 minutes. The 300 gsm of woven mat glass fiber and 150 gsm of woven mat jute fiber were placed layer by layer on the mould. Epoxy resin and hardner was mixed together in the ratio of 10:1 and quickly the prepared mixture was applied between all the layers of the fiber one by one. Preparation was carried out using handlayup method and left to cure. Care was taken so that to avoid the formation of voids. The cured component was released from the mould by heating the mould for 2 minutes in the oven. The real time fabrication was carried out for the modeled component. The fabricated prototype is presented in the figure 5.

\section{RESULTS AND DISCUSSION}

From the characterisation of the tabulation it was evident that there is possiblity of improvement on treatment of the fibers. The fiber loading also paved way for the increase in the mechanical properties like tensile, flexural 
and impact material strength. The fiber loading has permitted the benefit of loading carring capacity, since the addition of the fibers has favoured load distribusion evenly.

The tensile value has an improved percentage of $54 \%$ considering the value of neat epoxy. The lowest improvement is found in HP20, which is 15\% compairing with the neat epoxy. The treatment of the fibers showed improvement in them. This is because of the suface modifaction of the fibers, there by increasing the suface area of interaction between the resin and the fiber. The minimum to maximum value of their difference were found to 5 - 12 Mpa for HP20 -HP50 on treated fiber reinforcement. The highest value of the flexural strength was found to be $177 \mathrm{Mpa}$ for HP50. The improvement was found to be $72 \%$ compaired with the neat epoxy. Increase in the fiber loading has improved the flexural strength, this is because concentration of fibers does not favour the fiber pull out thereby increasing the flexural strength. There is no drastic change in the impact strength of the material but there is improvement when there is the fiber loading.

Figure 6: Maximum Equivalent Stress

\section{Maximum equivalent stress}

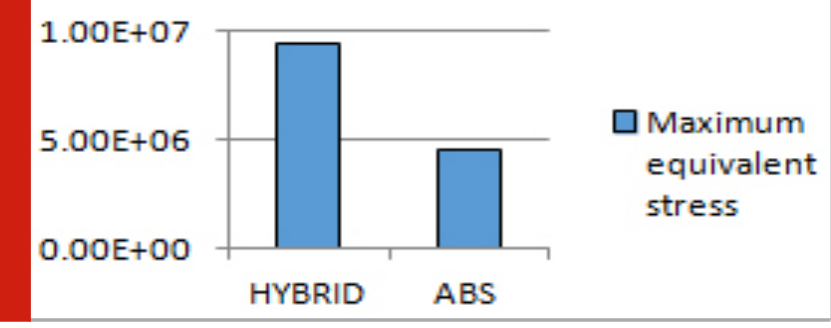

Figure 6: Maximum Equivalent Strain

\section{Maximum equivalent strain}

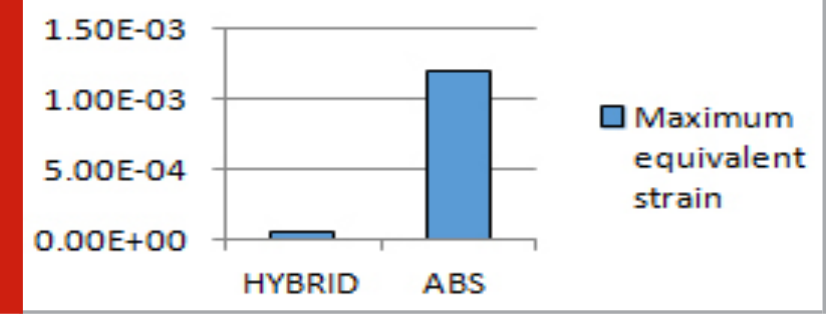

From the figure 6 it is evident that the resultant maximum equivalent stress for the hybrid mud guard is found to be $9.417 \times 106 \mathrm{~Pa}$ and for abs it is found to be $4.495 \times 106 \mathrm{~Pa}$. The stress for the hybrid mud guard is 210\% greater than ABS material. Hence the hybrid mud guard could with stand more load than the ABS, which results in smooth functioning of tyre. From the results obtained from figure 7 , the maximum equivalent strain was found to be $5.9772 \times 10^{-6}$ for the hybrid mud guard and for ABS material it was found to be $1.197 \times 10^{-03}$. The strain for the hybrid mud guard is very less when compared to the ABS and this shows that the hybrid mud guard could resist the loads with no deformation or with very little deformation of negligible value. The total deformation was found to be $6.493 \times 10^{-7}$ for the hybrid material and for ABS it was found to be $8.745 \mathrm{x}$ $10^{-1}$. The deformation results shows good stability in the hybrid material. The material seems to be a best suitable material for the functional application.

\section{CONCLUSION}

From the testing of the hybrid natural material composite, it is evedent that the processed fibers have better stength compared to the unprocessed fiber reinforced composites. There are similarities in the relative increase of flexural strength and the tensile strength of the composite materials as the fiber loading increases. The optimum volume percentage selected for the modelling of the mud gaurd was HP50.

According to the result obtained from the model analysis from the software, the equilateral stress on the mudgaurd has shown improved values and this is expected from the new hybrid material. The results of the mudgaurd has permitted only a less strain effects, showing it can take more.

The total deformation on the mudgaurd shown in the figure has provided that the ends of the mudgaurd shows little deviations. The observed deviation values provides a minimum change in the structure when compared with the values of the exsisting ABS materials. The analysis has shown greater difference in using the exsisting material and the new hybrid material. The jute-glassepoxy hybrid material has proved to be more improved than the exsisting one. It is understood that it can be used in higher strength and less weight applications. Keeping the same dimensions of existing Mud-guard experimental stress analysis can be conducted for various materials. Complicated shapes and size can also be developed and tested.

\section{REFERENCES}

Ayyappa Atmakuri \& Madhusudan Siddabathula., (2020). Analysis of Mechanical and Wettability Properties of Natural Fiber-Reinforced Epoxy Hybrid Composites, Polymers, 12 (2827), pp. 1-15.

Chabba, S., Matthews, G.F \& Netravali, A.N., (2005). Green composites using cross-linked soy flour and flax yarns, Journal of the royal society of chemistry, Green Chemistry, 7, pp. 576- 581.

Chandramohan, D, \&t John Presin Kumar, A., (2017). Experimental data on the properties of natural fiber particle reinforced polymer composite materials, 13, pp. 460-468,

Hanida H. P. S., Kang C. W. \& Nik Fuaad N. A., (2007). Agro-hybrid Composite: The Effects on Mechanical and 
Physical Properties of Oil Palm Fiber (EFB)/Glass Hybrid Reinforced Polyester Composites, Journal of Reinforced plastics and composites, 26 (2), pp. 203-218.

Kuruvilla Joseph, Sherely Annie Paul, Gem Mathew, Laly A. Pothen, \& Sabu Thomas., (2009). Preparation of Polypropylene Fibre/Banana Fibre Composites by Novel Commingling Method, Polymer Composites, 31 (5), pp. 816-824,.

Mochane M. J., Mokhena T. C., Mokhothu T. H., Mtibe A., Sadiku E. R., Ray S. S., Ibrahim I. D. \& Daramola 0. 0., (2018). Recent progress on natural fiber hybrid composites for advanced applications: A review, eXPRESS Polymer Letters,13 (2), pp. 159-198.

Mohanty A.K., Mishra M., \&t Drzal L.T., (2002). Sustainable composites using renewable resources: opportunities and the challenge in the green material world, Journal of polymer and the environment, 10, pp.19-26.

Murali Mohan Rao K. \&t MohanaRao K. (2007). Extraction and Tensile Properties of Natural Fibres: Vakka, Date and Bamboo, Journal of Composite Structure, 77 (3), pp. 288-295.

Narendra Reddy \&t Yang Yiqi., (2005). Bio Fibres from Agricultural By products for Industrial Applications,
Trend Bio Technol, 23, pp. 22-27.

Padmapriya S, Ramakrishna HV, Varadarajulu A \& Rai SK. (2005). Tensile flexural and chemical resistance properties of waste silk fabric reinforced epoxy laminates, Journal of Reinforced Plastic Composites; 24, pp 643-648.

Padmapriya S., Ramakrishna H. V., \&t Rai S. K., (2005). Utilization of waste silk fabric as reinforcement in epoxy phenol cashew nut shell liquid toughened epoxy resin: studies on mechanical properties, Journal of Reinforced Plastic Composites, 40, pp 1301-1311.

Palanikumar, K., Ramesh, M., \& Hemachandra Reddy, K., (2016). Experimental investigation on the mechanical properties of green hybrid sisal and glass fiber reinforced polymer composites, Journal of Natural Fibers, 13, pp. 321 - 331.

Rowell R.M., Hans J.S., \& Rowell J.S., (2000). Characterization and factors effecting fiber properties. Natural polymers and Agro fibers composite, pp. 115134.

Satyanarayana, K.G., Sukumaran, K., Kulkarni, A.G., Pillai S.G.K, and Rohatgi., (1983 ). Performance of Banana Fabric -Polyester Composites, Composite Structure 2, USA. 2, pp. 535-548 